\title{
A Integração das Disciplinas de Humanidades Médicas na Faculdade de Medicina da USP - Um Caminho para o Ensino
}

\section{The Integration of the Medical Humanities in the Faculdade de Medicina da USP - A Teaching Approach}

PALAVRAS-CHAVE:

- Humanização da Assistência;

-Humanidades;

-Educação Médica;

-Ensino;

-Integração;

-Currículo.

\section{KEY-WORDS:}

-Humanization of Medical

Assistance;

-Humanities;

-Medical Education;

-Teaching;

-Integration;

-Curriculum.

Recebido em: 19/01/2007

Reenviado em: 09/05/2007

Aprovado em: 05/07/2007
${ }^{1}$ Faculdade de Medicina da Universidade de São Paulo, São Paulo, Brasil.

${ }^{2}$ Hospital das Clínicas da Faculdade de Medicina da Universidade de São Paulo, São Paulo, Brasil.
Izabel Cristina Rios ${ }^{1}$ Ademir Lopes Junior ${ }^{1}$ Arthur Kaufman ${ }^{1}$ Joaquim Edson Vieira ${ }^{2}$ Marco de Tubino Scanavino ${ }^{2}$ Reinaldo Ayer de Oliveira ${ }^{1}$

\section{RESUMO}

A integração curricular, atualmente, é apontada como importante estratégia de ensino, processo que envolve várias etapas, trabalho e compromisso de grupo. Este artigo relata a experiência de integração das disciplinas de humanidades médicas da Faculdade de Medicina da Universidade de São Paulo (FMUSP). Ao longo de dois anos, constituiu-se um grupo composto pelas disciplinas da área de humanidades médicas, pesquisadores do Centro de Desenvolvimento da Educação Médica Professor Eduardo Marcondes (Cedem), alunos e professores de outras disciplinas interessados na área. Desenvolveu-se a integração temática e prossegue-se na integração metodológica.

\begin{abstract}
Currently curricular integration is considered an important educational strategy, a process involving several stages, work and group commitment. This paper relates the experience of the Faculdade de Medicina da Universidade de São Paulo (FMUSP) of integrating medical humanities disciplines. During two years a group was composed involving professors of medical humanities disciplines, researchers from the Center of Development of Medical Education Professor Eduardo Marcondes (Cedem) as well as students and professors of other disciplines interested in this area. The thematic integration has already been concluded and the methodological integration is in process.
\end{abstract}




\section{INTRODUÇÃO}

No mundo contemporâneo, os avanços tecnológicos propiciaram valiosas conquistas no campo da medicina, ao mesmo tempo em que o ensino e a organização do trabalho médico foram se tornando cada vez mais próximos da engenharia do organismo e distantes da essência do viver humano ${ }^{1}$.

$\mathrm{Na}$ área da saúde, chamamos "humanização" o resgate de valores humanísticos e o desenvolvimento de práticas que agregam à competência técnica o olhar humano sobre a totalidade dos acontecimentos que envolvem o adoecimento e seu desfecho. Apesar das críticas ao uso do termo "humanização" para nomear esse processo, o Ministério da Saúde ampliou seu alcance, transformando-o numa política pública do Sistema Único de Saúde. A Política Nacional de Humanização enfatiza a importância do exercício dos seus princípios desde a formação dos profissionais até os processos de gestão e organização do trabalho na saúde².

Nas diretrizes curriculares para os cursos de Medicina, o Ministério da Educação e Cultura estabeleceu como modelo do médico desejável para o país:

(...) O médico com formação generalista, humanista, crítica e reflexiva. Capacitado para atuar, pautado em princípios éticos, no processo de saúdedoença em seus diferentes níveis de atenção, com ações de promoção, prevenção, recuperação e reabilitação à saúde, na perspectiva da integralidade da assistência, com senso de responsabilidade social e compromisso com a cidadania, como promotor da saúde integral do ser humano ${ }^{3}$.

Nesse caminho, a Faculdade de Medicina da Universidade de São Paulo (FMUSP) elaborou um projeto pedagógico no qual ficou definido que o médico por ela formado deve ser:

um médico com sólida formação geral, formação básica profunda, treinamento nos três níveis de atenção à saúde (primário, secundário e terciário), elevada formação ética e humanista e apto a exercer sua profissão com responsabilidade social $e$ competência técnica4.

A formação dos alunos para o trabalho médico assim proposta envolve o desenvolvimento de competências éticas e valores morais num processo integrado à aprendizagem de conteúdos e práticas de caráter biomédico que tornam possível o redimensionamento da prática clínica para o exercício do ato de cuidar ${ }^{5,6,7}$.
Entretanto, o ensino de temas das áreas humanas para a construção da identidade e atitude médica, aqui e em vários lugares no mundo, é tarefa difícil que, somada a problemas estruturais, encontra resistências em alunos e professores $^{8,9}$.

Apesar da importância reconhecida, a ignorância e o obscurantismo frente aos temas das ciências humanas estão presentes na escola médica. Observa-se que muitos alunos e professores não consideram os aspectos humanísticos da prática médica como parte integrante do aprendizado da Medicina. Outros autores dizem que os alunos entram na faculdade de Medicina com o propósito de ajudar as pessoas, identificados com o ideal de médico que agrega competências cognitivas e humanistas, mas, ao longo da formação, vão perdendo a sensibilidade e privilegiando os aspectos cognitivos ${ }^{8,10}$.

Mudar essa cultura institucional requer o aprofundamento de conhecimentos na área e sua integração nas diversas disciplinas, além da criação de novas metodologias e estratégias de ensino, e o desenvolvimento de professores ${ }^{9,11}$.

A integração curricular, atualmente, é apontada como importante estratégia de ensino médico. É um processo que envolve várias etapas e requer um esforço consciente de comunicação, compreensão profunda dos objetivos coletivos e capacidade de trabalhar em grupo. $\mathrm{O}$ resultado mais instigante que essa metodologia pode oferecer talvez seja estimular no aluno a produção de sentido para os temas que serão essenciais no exercício da sua profissão ${ }^{12}$.

Nesse cenário, em 2004, o Centro de Desenvolvimento da Educação Médica Professor Eduardo Marcondes (Cedem) criou um espaço institucional para a aglutinação de alunos, professores e pessoas interessadas no assunto para discutir e elaborar estratégias que visassem a uma melhor inserção das humanidades no ensino médico e ao desenvolvimento ético e humano dos estudantes de Medicina.

O presente artigo narra o processo desencadeado desde então, a criação do grupo de trabalho e a integração curricular das disciplinas de humanidades da FMUSP como estratégia de ensino.

\section{O GRUPO DE INTEGRAÇÃO DAS DISCIPLINAS DE HUMANIDADES DA FMUSP}

Nas escolas médicas, a construção da postura ética e do pensamento crítico e reflexivo desenvolve-se a partir de disciplinas e condutas que se aprendem nas salas de aula, nos laboratórios e, principalmente, observando os mestres “à beira 
do leito", na prática cotidiana. Todas as disciplinas do currículo médico têm pontos de contato com a área de humanidades. Chamamos de Disciplinas de Humanidades Médicas aquelas cujos conteúdos estão diretamente ligados às áreas humanas no âmbito da Medicina - Filosofia, Ética,
Psicologia, Antropologia, Artes, Sociologia, História, Política ${ }^{13}$.

No currículo nuclear da graduação em Medicina da FMUSP, as disciplinas que trabalham especificamente temas humanísticos do primeiro ao quinto ano são:

\begin{tabular}{|l|l|l|}
\hline Disciplinas & $\begin{array}{l}\text { Período do curso em } \\
\text { que se desenvolve }\end{array}$ & Carga horária \\
\hline $\begin{array}{l}\text { Bases Humanísticas da } \\
\text { Medicina I }\end{array}$ & Primeiro ano & 30 horas \\
\hline $\begin{array}{l}\text { Bases Humanísticas da } \\
\text { Medicina II }\end{array}$ & Primeiro ano & 45 horas \\
\hline Psicologia Médica & Terceiro ano & 48 horas \\
\hline Cidadania e Medicina & Terceiro ano & 45 horas \\
\hline Bioética & Quarto ano & 30 horas \\
\hline Bioética Clínica & Quinto ano & 30 horas \\
\hline Carga horária total* & & 240 horas \\
\hline
\end{tabular}

* O curso de Medicina da USP em São Paulo conta com 11.025 horas (Estrutura Curricular, 2006).

O conteúdo programático dessas disciplinas é abrangente e percorre campos temáticos que envolvem:

- Aspectos socioculturais e políticos das práticas de saúde;

- Aspectos subjetivos na prática clínica;

- Aspectos éticos na área da saúde e na vida;

- O ser médico, sua formação, identidade e trabalho.

Em 2004, no Cedem, iniciamos um estudo sobre o conjunto dessas disciplinas. Promovemos debates com alunos e professores, e, desses encontros, constituiu-se um grupo de trabalho, inicialmente integrado por um coordenador de cada disciplina, cinco alunos, dois pesquisadores do Cedem e cinco outros professores, totalizando 18 pessoas. Posteriormente, juntaram-se ao grupo professores de outras disciplinas (Medicina Preventiva, Moléstias Infecciosas, Atenção Básica), enquanto outros saíram do grupo, mantendo-se mais ou menos o mesmo número total de participantes.

Uma pesquisadora do Cedem, na função de coordenadora do grupo, conduziu as reuniões, inicialmente quinzenais, depois mensais, nas quais o grupo analisou a situação das disciplinas de humanidades. A partir dessa análise, definiu como estratégia de ensino a integração curricular dessas disciplinas, especialmente a composição articulada dos conteúdos e métodos de ensino.

\section{ANÁLISE DE SITUAÇÃO DAS DISCIPLINAS DE HUMANIDADES EM 2004}

A coordenadora conduziu seis encontros, com técnica de grupo operativo, nos quais foram apontados os seguintes problemas em relação ao conjunto das disciplinas da área:
- A maioria dos alunos concordava quanto à importância da área para a formação médica, mas poucos se interessavam por ela;

- O desinteresse (segundo os próprios alunos) se devia ao modo como os temas eram apresentados: excessivamente teóricos e pouco ligados à prática médica;

- Os alunos admitiam que havia preconceitos em relação ao que não consideravam parte da medicina e que viam como uma "viagem", "filosofia", "coisas legais, mas que não interessam ao médico";

- Temas importantes não eram abordados, enquanto outros se repetiam sem continuidade e com a mesma abordagem;

- A maioria dos temas era apresentada como introdução de algo que não se aprofundava;

- As disciplinas desenvolviam seus temas de forma desarticulada das demais, inclusive das outras disciplinas da área de humanidades;

- No conjunto dos professores dessas disciplinas, havia bons professores e outros sem preparo adequado para a condução do trabalho nos grupos de discussão;

- Havia uma dissociação entre o que se discutia nessas disciplinas e o que se observava na prática;

- Na prática cotidiana, a área de humanidades não tinha reconhecimento institucional, embora, no discurso público, sua importância fosse reiterada;

- O acréscimo devido a essas disciplinas é subjetivo e de difícil mensuração, o que poderia estar causando a falsa impressão imediata de que elas não produzem efeitos. 


\section{PLANO DE TRABALHO}

Dessa análise de situação, o grupo definiu seus princípios educacionais, delimitou dois campos de ação, um campo didáticopedagógico e outro de âmbito institucional, e desenhou um plano de trabalho que se desenvolveu em 2005 e 2006.

Os princípios educacionais definidos foram:

- Estímulo à participação do aluno;

- Construção de conhecimento consistente;

- Estímulo ao desenvolvimento pessoal e profissional;

- Estímulo ao pensamento ampliado e crítico da prática médica.

No campo didático-pedagógico, o grupo optou por trabalhar pela integração curricular como método, definindo a princípio duas etapas: a integração temática e a integração metodológica. A primeira seria entendida como um alinhamento dos temas e conteúdos desenvolvidos pelas disciplinas de forma consciente, com continuidade e de acordo com o momento da formação do aluno, e a segunda como o desenvolvimento de professores para exercer metodologias adequadas às temáticas.

No âmbito institucional, o grupo elegeu duas ações principais: a divulgação do grupo e suas idéias, e a articulação com outras disciplinas e espaços institucionais, tais como Comitê de Humanização, Comitê de Bioética, Comissão de Ética Médica, Comissões de Ética e Pesquisa, Programa Tutores, Ouvidorias e outros.

No plano de trabalho, o grupo estabeleceu como meta para 2005 a integração temática e a construção do currículo integrado das disciplinas de humanidades. E para 2006, a implantação do currículo pelas disciplinas e o planejamento da divulgação do grupo e da integração metodológica. Ficou acordado que o grupo estaria, a qualquer momento, aberto à participação de outras disciplinas e pessoas interessadas no trabalho.

\section{A INTEGRAÇÃO TEMÁTICA}

Ao longo do ano de 2005, foram realizados oito encontros mensais para maturação da proposta e duas oficinas de trabalho, organizadas pela coordenadora do grupo, para feitura do currículo integrado.
Na primeira oficina, foram expostos os temas de cada disciplina, as aulas e os principais problemas. Para surpresa, a maioria dos integrantes do corpo docente desconhecia o conteúdo das outras disciplinas de sua área, o que explicava a queixa dos alunos quanto à repetição dos temas com a mesma abordagem. A título de exemplo, um mesmo simulado de julgamento pelo CRM havia sido feito por duas disciplinas da área, para a mesma turma de alunos, sem que os docentes soubessem do fato.

A segunda oficina teve como objetivo a escolha dos conteúdos e das aulas de cada disciplina da área de humanidades de acordo com os princípios educacionais do grupo e o momento de aprendizado do aluno. Nelas, definiram-se os temas essenciais para a formação humana do médico, o melhor momento do curso para serem desenvolvidos, a necessidade de aprofundamento e a disposição dos temas na estrutura programática de cada disciplina.

Ao mesmo tempo, professores de disciplinas de outras áreas se juntaram ao grupo, ampliando pontos de vista sobre as humanidades e inserindo temas em disciplinas não específicas.

No final de 2005, o grupo obteve o primeiro resultado do seu trabalho de aglutinação, o Currículo Integrado das Disciplinas de Humanidades da FMUSP, uma grade na qual as disciplinas de humanidades do currículo nuclear definiram seus temas e conteúdos de forma conjunta. Eis sua descrição (como apresentado aos alunos):

\section{Bases Humanísticas da Medicina I - (MPS 219)}

Inserido numa dada sociedade e imerso em determinada cultura, o paciente possui história, valores e crenças. Frente à grande evolução da Medicina, faz-se imperioso o resgate da humanização para prevenir o risco de um reducionismo tecnológico na prática clínica contemporânea. As disciplinas Bases Humanísticas da Medicina I e II destinam-se, respectivamente, a promover o estudo de temas fundamentais à prática médica, com abordagem ampla e multifocal (BHM I) e abordar essa temática da perspectiva do estudante de Medicina (BHM II). 


\section{Bases Humanísticas da Medicina I - (MPS 219)}

\begin{tabular}{|l|}
\hline Humanização: a humanização das relações na sociedade atual \\
\hline $\begin{array}{l}\text { Sexualidade: saúde e sexualidade, diversidade se xual, hábitos e estilos de vida e } \\
\text { comportamento sexual hoje }\end{array}$ \\
\hline $\begin{array}{l}\text { Uso de drogas: o uso de drogas na sociedade atual, aspectos sociais, legais, } \\
\text { econômicos e médicos }\end{array}$ \\
\hline $\begin{array}{l}\text { A relação da cultura e da religião com a saúde: a articulação de aspectos } \\
\text { socioculturais para a preservação ou perda da saúde }\end{array}$ \\
\hline $\begin{array}{l}\text { Tecnologia: a tecnicização, suas implicações no aspecto humanístico das relações } \\
\text { humanas e no estilo de vida atual }\end{array}$ \\
\hline $\begin{array}{l}\text { Direitos Humanos: os direitos e deveres do homem, aspectos históricos até a } \\
\text { Declaração dos Direitos Humanos }\end{array}$ \\
\hline $\begin{array}{l}\text { O corpo humano na perspectiva não médica: outras perspectivas para a compreensão } \\
\text { do homem }\end{array}$ \\
\hline
\end{tabular}

\section{Bases Humanísticas da Medicina II - (MPS 220)}

\begin{tabular}{|l|}
\hline $\begin{array}{l}\text { A formação médica: o currículo atual e a formação humanística e técnica do } \\
\text { estudante }\end{array}$ \\
\hline A sexualidade e o estudante de Medicina \\
\hline Vocação e identidade do aluno de Medicina: isso existe? \\
\hline $\begin{array}{l}\text { O estudante de Medicina e suas relações: colegas, amigos, professores, parcerias } \\
\text { afetivas e família }\end{array}$ \\
\hline $\begin{array}{l}\text { Aspectos éticos do estudante de Medicina: referencial ético no aprendizado e no } \\
\text { exercício da Medicina }\end{array}$ \\
\hline A violência e o estudante de Medicina: dos “trotes” à agressividade do curso médico \\
\hline O uso de drogas na graduação médica: razões e conseqüências \\
\hline
\end{tabular}

\section{Psicologia Médica - (MPS 0626)}

O curso visa a transmitir ao aluno conhecimentos a respeito de problemas biopsicossocioculturais envolvidos no exercício da Medicina. Mostrar ao futuro médico de qualquer especialidade as situações mais freqüentes na clínica, os modelos de formulação de diagnóstico psicológico e os obstáculos comunicacionais à intervenção médica. Este aprendizado é fundamental para aumentar a adesão do paciente ao tratamento e instrumentar o futuro médico a reconhecer os níveis de comunicação verbal e não verbal no trato com o paciente, a família e a sociedade. 


\section{Psicologia Médica - (MPS 0626)}

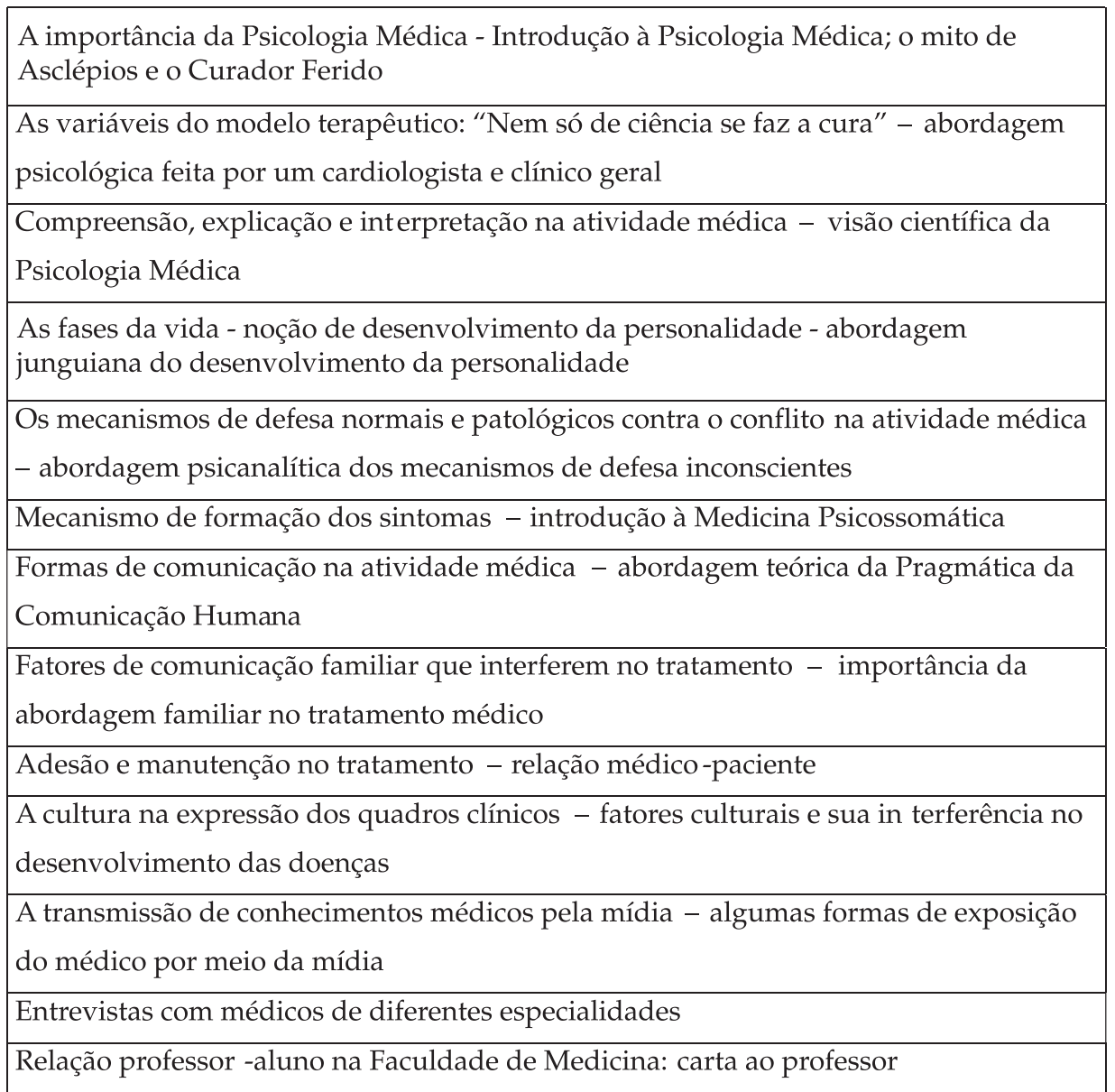

\section{Cidadania e Medicina - (MSP 0667)}

A cidadania diz respeito a direitos civis, políticos e sociais. Direitos civis são os fundamentais à vida, à liberdade, à propriedade, à igualdade perante a Lei. Os direitos políticos referem-se à participação do cidadão no governo da sociedade, e os direitos sociais garantem a participação nos bens coletivos (educação, trabalho, aposentadoria e saúde). Nesse contexto, se pretende discutir o papel do médico na sociedade, com ênfase em uma possível - ou não - responsabilidade especial que o exercício da profissão possa lhe conferir.

\begin{tabular}{|l|}
\hline Cidadania, políticas públicas e práticas profissionais \\
\hline Julgamento simulado do Cremesp \\
\hline O princípio da justiça no sistema de saúde brasileiro \\
\hline Relação médico -paciente: uma questão de Direito \\
\hline A atuação da equipe multiprofissional de saúde: um exercício de cidadania \\
\hline Atualidades bioéticas e a Lei do Ato Médico \\
\hline Doutores da alegria: uma lição de cidadania \\
\hline Atualidades bioéticas: uma situação bioética da atualidade discutida criticamente \\
\hline
\end{tabular}


A história desse processo começa dois anos antes da formação do grupo, nas avaliações e fóruns institucionais, nos quais as disciplinas de Humanidades Médicas sempre apareciam entre as piores do ponto de vista dos estudantes. Até se reunir o grupo todo e iniciar o trabalho conjunto de integração, cada disciplina procurava resolver seus problemas sozinha.

Os estudantes tiveram importância fundamental para instigar os professores e a instituição para promover mudanças nessas disciplinas, o que levou à constituição do grupo de integração. Desde o início, havia alguns temores. Primeiro: várias mudanças já haviam sido feitas em cada disciplina, e a avaliação pelo alunado era a mesma. Segundo: embora houvesse apoio do presidente da Comissão de Graduação, o grupo temia se envolver em um "trabalho à toa" se, no momento da implantação das mudanças, não tivesse as condições, o reconhecimento e o legítimo apoio da instituição.

A resposta para o primeiro problema foi perceber que a integração de fato nunca tinha sido tentada, uma vez que as mudanças propostas até então eram pontuais. A exposição de cada disciplina, aula a aula, para todos os professores da área, era algo novo e fundamental para o conhecimento da realidade. Para o segundo problema, a resposta veio com o respaldo político da Comissão de Graduação com a presença efetiva do presidente da Comissão de Graduação em algumas reuniões. Além disso, convidar professores de outras disciplinas, mas que tinham interesse na área, enriqueceu muito o trabalho e fez o grupo perceber a possibilidade de uma intervenção maior no currículo, além do apenas esperado para as disciplinas de humanidades.

Outro problema enfrentado foi a participação estudantil. De mil alunos de graduação, apenas três participaram efetivamente do processo, fato muitas vezes apontado como prova da falta de interesse pela área.

Sobre essa questão, a fala de uma aluna participante foi suficiente: "Claro que é necessário buscar e permitir o envolvimento de todos os alunos na discussão, deixar essa porta aberta. Mas nem todos virão, alguns porque não gostam, outros porque não se interessam, e outros porque simplesmente não têm tempo. Porém, se mesmo os alunos que se interessam muito pelo tema não se sentem satisfeitos intelectual e emocionalmente com o desempenho e o espaço das humanidades dentro do curso médico, será que os que não têm tanta afinidade pela área se interessarão?".

Estava claro que o problema não era só os temas escolhidos, mas principalmente o modo como eram abordados. Aos poucos, o grupo concordou em que a integração deveria alcançar não apenas os conteúdos programáticos, mas também a metodologia como forma de despertar o interesse dos alunos pela área. Não há (nem nunca haverá) mil alunos participando diretamente do processo, mas que se valorize e aproveite a disposição dos poucos participantes como uma forma de compreender os interesses do corpo estudantil.

Por fim, outra dificuldade enfrentada foi a do próprio trabalho em equipe. Todos os professores e alunos têm muitas outras atividades na instituição e pouco tempo. As pessoas se revezavam nas reuniões, o que levava à repetição e retomada excessiva da mesma discussão. A indicação de uma coordenadora para o grupo, com a função de promover o trabalho de grupo, organizar as atas e documentos, planejar o desenho e redação de projetos, repassar as informações para todos os membros do grupo, acompanhar o andamento de todas as tarefas e, mais importante, coordenar as reuniões foi fundamental para que todos participassem do processo.

A construção de um folder sobre a integração das disciplinas de Humanidades para a divulgação junto aos alunos permitiu ao grupo perceber o trabalho de equipe que começava a apresentar resultados visíveis.

\section{CONSIDERAÇÕES FINAIS}

Nos primórdios da medicina, lidar com a dor era o principal objetivo do médico na relação com o doente, e o sucesso da intervenção era o seu alívio - o termo "doente" deriva da palavra latina dolentia, que significa aquele que sente dor.

Historicamente, consideramos que o fundamento da medicina é o doente e que o ensino deve ser centrado na relação humana que se estabelece entre o estudante e o doente. Não existem doenças sem que existam doentes.

Assim, a prática médica está centrada na relação entre pelo menos duas pessoas. Entre o médico e o doente, como em qualquer relacionamento entre pessoas, há um conflito subjacente, pois do encontro das pessoas surgem emoções próprias do ser humano de forma muito menos controlável do que se imagina. Mas, como diz Cohen ${ }^{16}$, é dessa vivência emocional que se faz o relacionamento:

O encontro com outra pessoa sempre provoca estado de turbulência emocional, pois significa sair de um estado afetivo para adaptar-se à presença do outro, que será sentido das mais diferentes formas. Entretanto, será essa percepção emocional que nos permitirá avaliar a presença do outro, podendo com ele se relacionar.

O desenvolvimento da competência ética e emocional necessária ao exercício da medicina parece bastante comprometido nos tempos atuais, inevitavelmente nos levando à questão formulada por Schraiber ${ }^{17}$ sobre a formação humanística do aluno de Medicina:

Até que ponto poderemos atuar pela via da formação do médico, em especial pelo aprimoramento do ensino técnico e científico da escola médica e pela 
revalorização da educação como desenvolvimento não apenas técnico, mas ético, moral e político do médico? Este último aspecto refere-se diretamente à maior consciência da dimensão econômico-social da medicina è introjeção do valor da responsabilização social do médico, desenvolvendo um comportamento de maior compromisso de cada médico no exercício de sua prática.

Aprofundando essa questão, Kaufman ${ }^{18}$ enfatiza a importância da relação professor-aluno no processo ensinoaprendizagem:

A importância primordial desta interação é que normalmente ela serve de modelo para a relação médico-paciente: normalmente o estudante trata o paciente da mesma forma que costuma ser tratado pelo professor.

Numa sociedade onde o esmaecimento dos valores humanísticos e a violência no comportamento e nas relações entre as pessoas são presenças cotidianas, a reflexão sobre temas das ciências humanas, noâmbito da medicina, écondição imprescindível para a passagem de estudante a médico. A conduta moral e a competência ética são resultados do desenvolvimento da capacidade dos indivíduos para a busca do bem individual e coletivo, busca que também considera a perspectiva dos outros e não elege a si mesmo como única referência para a compreensão do mundo ${ }^{5}$. Não se trata, pois, de habilidade inata, mas de aprendizado, conquista e exercício que deve envolver a todos nas experiências de vida e nos espaços formais de educação. A capacidade de tomar decisões morais é resultado do processo de maturação individual, competência adquirida desde estímulos no campo da moral.

Nesse contexto, as disciplinas de humanidades têm uma importante missão a cumprir: promover a inclusão curricular de temas essenciais para a prática médica humanizada de maneira que faça sentido para o aluno, envolvendo os professores numa verdadeira mudança de cultura educacional. Nas palavras de Vieira19: "A prática da observação clínica, mesmo que iniciada nos primeiros anos, associada à reflexão dessas observações, traz acréscimos ao olhar clínico e pode humanizá-lo intensamente".

Humanidade, humanitas, "a forma acabada, ideal ou espírito do homem", da qual derivou o substantivo humanismo e seu conceito, vem dos gregos. Pode-se entender, também, a humanidade como a natureza racional do homem, dotada de dignidade e, portanto, fim para si mesma. Esse é o significado que a palavra assume no imperativo categórico de Kant: “Age de tal maneira que trates a Humanidade tanto na tua pessoa quanto na pessoa de qualquer outro, sempre também como fim e não somente como meio" 20 .

\section{Ainda de $\operatorname{Kant}^{20}$ é a definição:}

Humanismo significa, por um lado, o sentimento universal de simpatia e, por outro, a faculdade de poder comunicar pessoal e universalmente; essas são duas propriedades que, juntas, constituem a sociabilidade própria da humanidade, graças à qual ela se diferencia do isolamento animal.

Recuperar dos filósofos a humanitas opacificada na contemporaneidade talvez possa nos aproximar mais não só dos doentes, mas de nossa própria essência humana e nos alimentar a vida com toques de alegria, prazer e emoção, ainda que em nossa condição de viventes de um cotidiano, na maioria das vezes, marcado por profunda solidão.

\section{REFERÊNCIAS}

1. Schraiber LB. No encontro da técnica com a Ética: o exercício de julgar e decidir no cotidiano do trabalho em Medicina. Interface 1997; 1(1): 123-38.

2. Brasil. Ministério da Saúde. HumanizaSus: Política Nacional de Humanização. Brasília: Ministério da Saúde, 2004 (Caderno do Ministério da Saúde).

3. Brasil. Ministério da Educação. Conselho Nacional de Educação. Diretrizes Curriculares Nacionais do curso de graduação em Medicina. [online]. [capturado 12 jan 2007]. Disponível em: http://www.abem-educmed.org.br/ cne_minuta_resolucao.htm

4. Martins MA. Projeto Pedagógico do Curso de Medicina da FMUSP [online]. [capturado 02 maio 2007]. Disponível em: http:/ / www.fm.usp.br/cedem/discussao/projeto.php

5. Rego S. A formação ética dos médicos: saindo da adolescência com a vida (dos outros) nas mãos. Rio de Janeiro: Fiocruz; 2005.

6. Ayres JRCM. Cuidado e reconstrução das práticas de saúde. Interface 2004; 8(14): 73-91.

7. Scanavino MT. Aids: A Relação Médico-paciente. São Paulo: Via Lettera; 2004.

8. Hafferty FW, Franks R. The hidden curriculum, ethics teaching, and the structure of medical education. Acad. Med 1994; 69(11): 861-71.

9. Hekelman FP, Snyder CW, Alemagno S, Hull AL, Vanek E. Humanistic teaching attributes of primary care physicians, Teach. Learn. Med 1995; 7(1): 29-36. 
10. Silva GSN. A construção do 'ser médico' e a morte: significados e implicações para a humanização do cuidado. São Paulo; 2007. Tese [Doutorado]. Universidade de São Paulo.

11. Schramm RF, Rego S, Braz M, Palácios M. Bioética: riscos e proteção. Rio de Janeiro: UFRJ/Fiocruz; 2005.

12. Harden RM. The integration ladder: a tool for curriculum planning and evaluation. Med. Educ 2000; 34(7): 551-57.

13. Pereira RTMC. O ensino da medicina através das humanidades médicas : análise do filme And the band played on e seu uso em atividades de ensino/ aprendizagem em educação médica. São Paulo; 2004. Tese [Doutorado] - Universidade de São Paulo.

14. Hahn SR, Croen LG, Kupfer R, Levin G. A method for teaching human values in clinical clerkship trough group discussion. Teach. Learn. Med 1991; 3(3): 143-50.

15. Anastasiou LGC, Alves LP. Processos de Ensinagem na Universidade. Joinville: Univille; 2006.

16. Cohen C. Bioética e sexualidade nas relações profissionais. São Paulo: Associação Paulista de Medicina; 1999.
17. Schraiber, LB. Medicina tecnológica e prática profissional contemporânea: novos desafios, outros dilemas. São Paulo; 1997. Tese (Livre-Docência) - Universidade de São Paulo.

18. Kaufman A. Teatro Pedagógico: bastidores da iniciação médica. São Paulo: Agora; 1992.

19. Vieira JE. Definição de necessidades sociais para o ensino médico. Rev. Brás. Educ. Med 2003; 27 (2):153-57.

20. Abbagnano N. Dicionário de filosofia. 4 ed. São Paulo: Martins Fontes; 2000.

\section{CONFLITOS DE INTERESSE}

Declarou não haver.

\section{ENDEREÇO PARA CORRESPONDÊNCIA}

CEDEM - Centro de Desenvolvimento da Educação Médica Professor Eduardo Marcondes - FMUSP

Av. Dr. Arnaldo, 455 - Cerqueira César

01246-903 - São Paulo - SP

E-mail: humano@usp.br 